\title{
Monolithic mass sensor fabricated using a conventional technology with attogram resolution in air conditions
}

\author{
J. Verd, ${ }^{\text {a) }}$ A. Uranga, G. Abadal, J. Teva, and F. Torres \\ Department of Electronic Engineering, Universitat Autònoma de Barcelona, 08193 Bellaterra, Spain \\ F. Pérez-Murano \\ Institut de Microelectrònica de Barcelona, IMB-CNM-CSIC, 08193 Bellaterra, Spain \\ J. Fraxedas \\ Institut de Ciència de Materials de Barcelona, ICMAB-CSIC, 08193 Bellaterra, Spain \\ J. Esteve \\ Institut de Microelectrònica de Barcelona, IMB-CNM-CSIC, 08193 Bellaterra, Spain \\ N. Barniol \\ Department of Electronic Engineering, Universitat Autònoma de Barcelona, 08193 Bellaterra, Spain
}

(Received 20 February 2007; accepted 10 April 2007; published online 2 July 2007)

\begin{abstract}
Monolithic mass sensors for ultrasensitive mass detection in air conditions have been fabricated using a conventional $0.35 \mu \mathrm{m}$ complementary metal-oxide-semiconductor (CMOS) process. The mass sensors are based on electrostatically excited submicrometer scale cantilevers integrated with CMOS electronics. The devices have been calibrated obtaining an experimental sensitivity of 6 $\times 10^{-11} \mathrm{~g} / \mathrm{cm}^{2} \mathrm{~Hz}$ equivalent to $0.9 \mathrm{ag} / \mathrm{Hz}$ for locally deposited mass. Results from time-resolved mass measurements are also presented. An evaluation of the mass resolution have been performed obtaining a value of $2.4 \times 10^{-17} \mathrm{~g}$ in air conditions, resulting in an improvement of these devices from previous works in terms of sensitivity, resolution, and fabrication process complexity. (C) 2007 American Institute of Physics. [DOI: 10.1063/1.2753120]
\end{abstract}

Cantilever-based sensors are very attractive transducers for physical, chemical, and biological sensors based on micro-/nanoelectromechanical systems ${ }^{1-11}$ (NEMSs) due to its simplicity, wide range of sensing domains, and extremely high sensitivity when cantilever is scaled down into submicrometer scale dimensions. ${ }^{6-10}$ One approach is the use of these cantilevers in dynamic mode for mass sensing applications where the mass is measured as a change of the resonance frequency. Monolithic integration of the cantileverbased transducer with readout electronics provides interesting advantages in terms of size, portability, and $\operatorname{cost}^{10,11}$ in front of the use of optical readout techniques commonly used. ${ }^{2-9}$

In previous works, ${ }^{10}$ a post-complementary metal-oxidesemiconductor (CMOS) fabrication process based on a combination of electron beam lithography and direct write laser lithography has been used in order to define and release the cantilever of fully integrated mass sensors. In this letter, the mechanical structures are defined directly during the standard CMOS process used to fabricate the overall sensor (cantilever-based transducer plus readout circuitry [Fig. 1(a)], without the need of any additional lithographic process. ${ }^{12}$ The reported results corresponding to calibration, real time mass measurements, and resolution analysis indicate the benefits in terms of resolution and operation stability of a fully integrated mass sensor operating in air conditions, which has been fabricated using a conventional CMOS technology.

Cantilever structures $10 \mu \mathrm{m}$ long $(l), 600 \mathrm{~nm}$ wide $(w)$, and $750 \mathrm{~nm}$ thick $(t)$ [Fig. 1(b)] have been fabricated by

\footnotetext{
${ }^{a)}$ Electronic mail: jaume.verd@uib.es
}

using the top metal layer of a commercial $0.35 \mu \mathrm{m}$ CMOS technology. ${ }^{12,13}$ We use a three-electrode configuration constituted by the cantilever that is biased at a dc voltage $\left(V_{\mathrm{dc}}\right)$ and two electrodes for electrostatic excitation $\left(V_{\mathrm{ac}}\right)$ and capacitive readout purposes $\left(V_{\text {sense }}\right)$, respectively. The cantilever displacement is detected with a full-custom designed readout $C M O S$ circuit with a high-sensitivity and low-noise front-end stage. ${ }^{14}$ The electrical scheme used presents an input capacitance as low as $11 \mathrm{fF}$ and an input refereed noise of $21 \mathrm{nV} / \mathrm{Hz}^{1 / 2}$, obtaining a cantilever displacement resolution of only $38 \mathrm{fm} / \mathrm{Hz}^{1 / 2}$, which is comparable to state-ofthe-art of optical detection.

The mass sensing principle is based on measuring the resonance frequency shift of the cantilever due to the accreted mass. This frequency shift is determined from the transmission frequency response $\left(S_{21}\right.$ parameter) of the devices which is measured by a network analyzer (Agilent E5100A) with $50 \Omega$ impedance.

The mass sensitivity of the cantilever operated in the fundamental lateral mode, for locally deposited mass, can be expressed as

$$
\frac{\Delta M_{\mathrm{loc}}}{\Delta f_{o}}=\mathfrak{R}^{-1}=-\frac{2 M_{\mathrm{eff}}}{f_{o}} \quad(\mathrm{~kg} / \mathrm{Hz}),
$$

where $\mathfrak{R}$ is the cantilever mass responsitivity, ${ }^{15} M_{\text {eff }}$ is the cantilever effective mass, and $f_{o}$ its resonance frequency. For a rectangular cantilever, $M_{\text {eff }} \approx 0.24 \rho l w t$, where $\rho$ is the cantilever mass density. In the case of distributed mass over the cantilever area $[A=(l \times t)]$, the sensitivity may be given in terms of area using next expression 


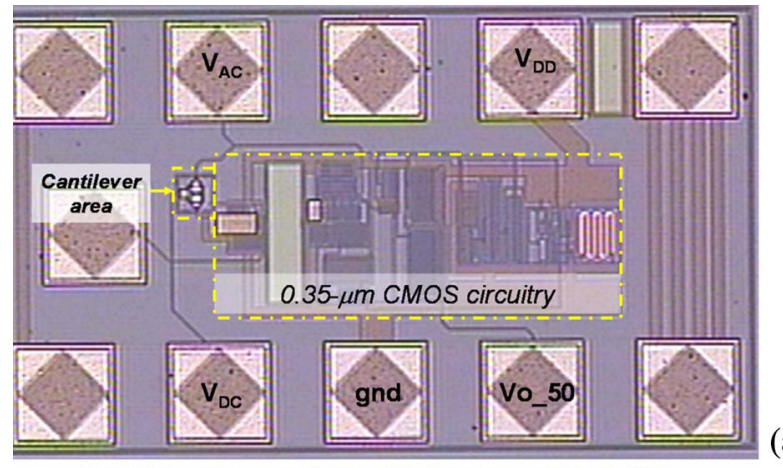

(a)

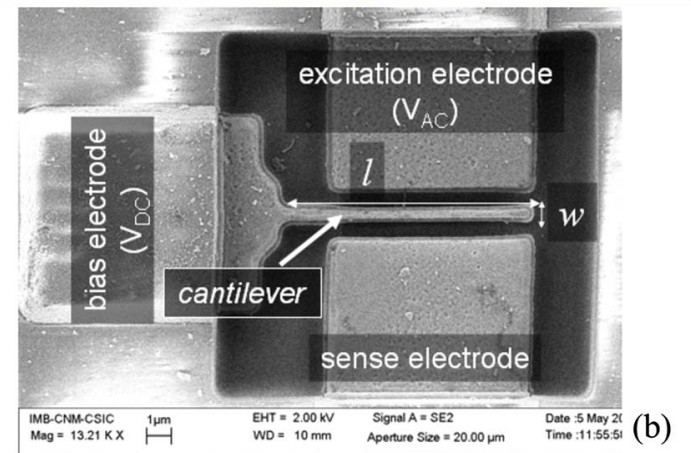

FIG. 1. (Color online) (a) Photograph of the cantilever-based mass sensor monolithically integrated with full-custom designed electronics in AMS's $0.35 \mu \mathrm{m}$ CMOS process(Ref. 13). (b) Scanning electron microscopy image of a fabricated $10 \mu \mathrm{m}$ long and $0.6 \mu \mathrm{m}$ width metal cantilever resonator with a three-electrode configuration.

$$
\frac{\Delta M_{\text {area }}}{\Delta f_{o}} \frac{1}{A} \equiv \mathfrak{R}_{\text {area }}^{-1} \approx \frac{\mathfrak{R}^{-1}}{0.24 A} \quad\left(\mathrm{~kg} / \mathrm{m}^{2} \mathrm{~Hz}\right)
$$

Assuming aluminum (Al) as structural layer of the fabricated cantilevers with a density of $2.7 \times 10^{3} \mathrm{~kg} / \mathrm{m}^{3}$, the theoretical mass sensitivities, for local and distributed mass depositions are $8.9 \times 10^{-19} \mathrm{~g} / \mathrm{Hz}$ and $6.2 \times 10^{-11} \mathrm{~g} / \mathrm{cm}^{2} \mathrm{~Hz}$, respectively, resulting in an improvement with respect to devices presented before. ${ }^{10}$

The calibration of these sensors was performed on two devices by two successive depositions of magnesium fluoride

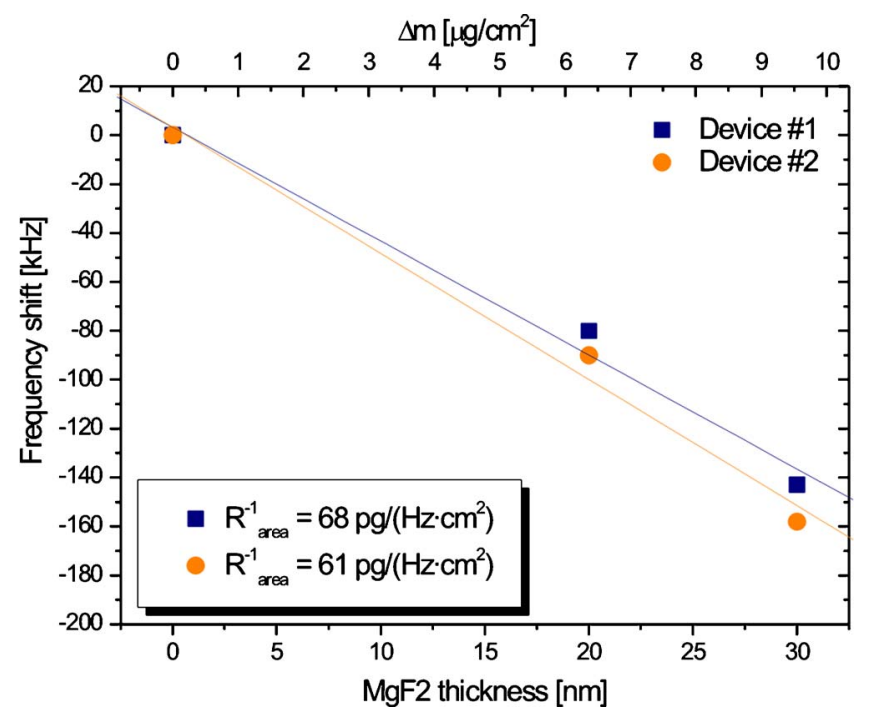

FIG. 2. (Color online) Plot of the resonance frequency shifts induced by sequential depositions of $\mathrm{MgF}_{2}$ layers of 20 and $10 \mathrm{~nm}$ thick, respectively. The density of $\mathrm{MgF}_{2}$ is $3.2 \times 10^{3} \mathrm{~kg} / \mathrm{m}^{3}$. The equivalent accreted mass $(\Delta m)$ for a $10 \times 0.6 \mu \mathrm{m}^{2}$ cantilever is indicated in the top $x$ axis.

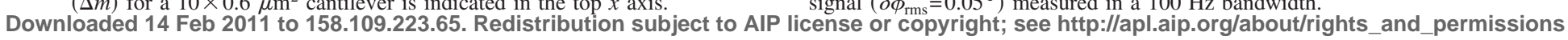

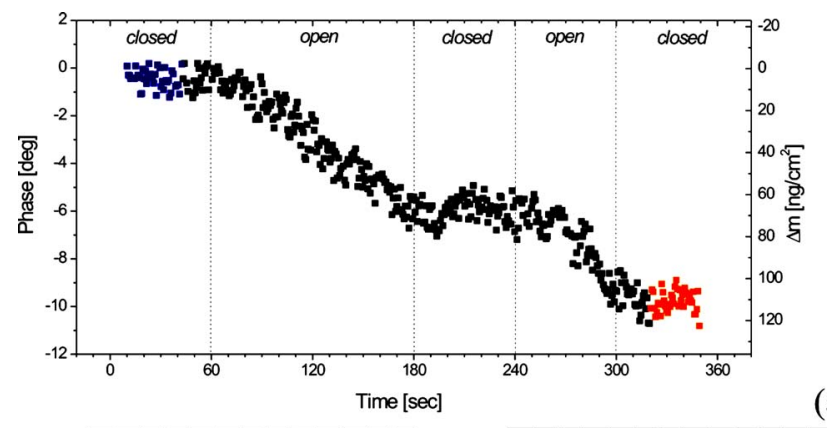

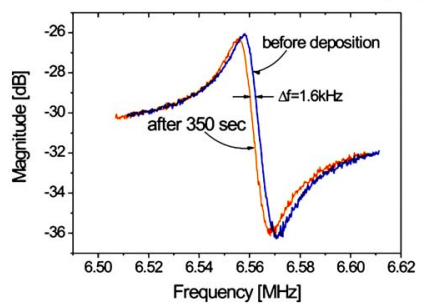

(b)

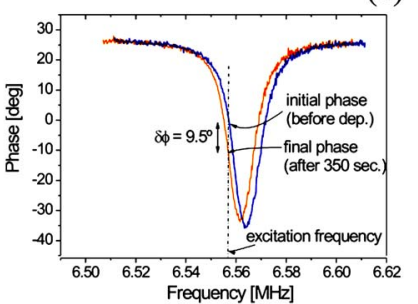

(c)
FIG. 3. (Color online) Real time attogram-scale mass sensing experiment with a monolithic mass sensor. The device is biased with $V_{\mathrm{dc}}=20 \mathrm{~V}$ and excited $\left(V_{\text {ac }}\right)$ with $-30 \mathrm{dBm}(50 \Omega)$. (a) Zero-span plot of the $S_{21}$ parameter phase showing the changes induced by successive expositions to a gold atom flux (deposited equivalent mass per area is already indicated). $S_{21}$ parameter frequency response, magnitude (b), and phase (c), before any deposition (time $=0 \mathrm{~s}$ ) and after successive depositions $($ time $=360 \mathrm{~s}$ ).

$\left(\mathrm{MgF}_{2}\right)$ thin layers of 20 and $10 \mathrm{~nm}$ thick over the devices by means of electron beam deposition. Figure 2 shows the frequency shifts, measured in air conditions (atmospheric pressure and room temperature), induced by these depositions obtaining an experimental average sensitivity, assuming the cantilever dimensions previously indicated, of around 6.3 $\times 10^{-11} \mathrm{~g} / \mathrm{cm}^{2} \mathrm{~Hz}$ equivalent to a local mass sensitivity of $9.2 \times 10^{-19} \mathrm{~g} / \mathrm{Hz}$ that is in agreement with theoretical values.

Time-resolved mass measurement experiments have been performed by exposing the device to a gold atom flux, ${ }^{16}$ controlled by a shutter, and monitoring the changes of the transmission parameter $\left(S_{21}\right)$. Figure 3(a) plots the $S_{21}$ parameter phase for zero-span measurements at the resonance frequency when the atom flux is opened and closed successively. $S_{21}$ parameter phase remains constant when the shut-

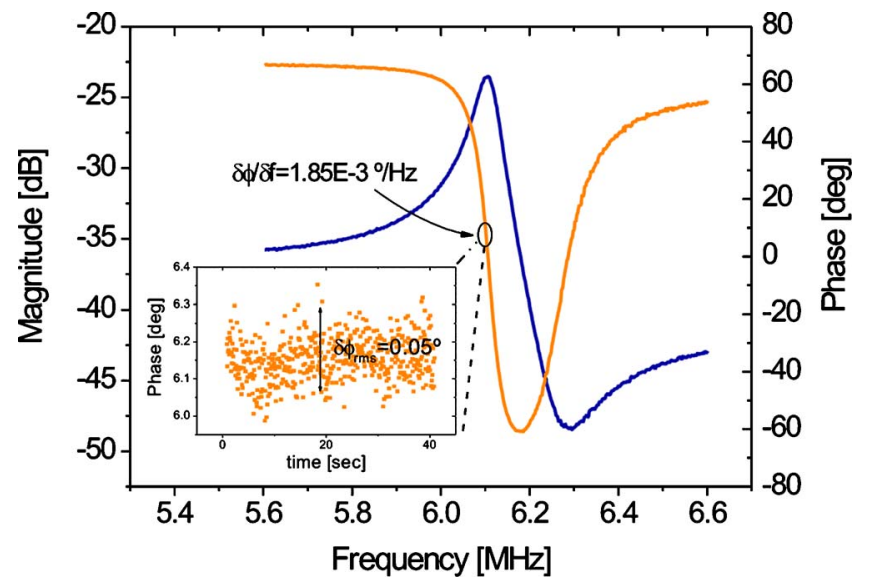

FIG. 4. (Color online) Frequency response obtained in air, atmospheric pressure, and room temperature, with $V_{\mathrm{dc}}=60 \mathrm{~V}$ and $V_{\mathrm{ac}}=-10 \mathrm{dBm}(50 \Omega)$. The resonance frequency is around $6.1 \mathrm{MHz}$ and an electrical quality factor of around 100 is measured. The inset shows the fluctuation of the phase signal $\left(\delta \phi_{\mathrm{rms}}=0.05^{\circ}\right)$ measured in a $100 \mathrm{~Hz}$ bandwidth. 
TABLE I. Calculated and experimental values of mass sensitivity and mass resolution for distributed and locally mass deposition for a cantilever. Experimental measurements have been performed in air, atmospheric pressure, and room temperature. A quality factor of 100 and root-mean-square oscillation amplitude of $30 \mathrm{~nm}$, consistent with a linear response, have been used for intrinsic mass resolution determination.

\begin{tabular}{ccccc}
\hline \hline Case & $\begin{array}{c}\left|\mathfrak{R}^{-1}\right|_{\text {calc. }} \\
(\mathrm{g} / \mathrm{Hz})\end{array}$ & $\begin{array}{c}\left|\mathfrak{R}^{-1}\right|_{\text {expt. }} \\
(\mathrm{g} / \mathrm{Hz})\end{array}$ & $\begin{array}{c}\delta M_{\text {expt. }} \\
(\mathrm{g})\end{array}$ & $\begin{array}{c}\delta M_{\text {int }} \\
(\mathrm{g})\end{array}$ \\
\hline $\begin{array}{c}\text { Distributed } \\
\left(\mathrm{cm}^{-2}\right)\end{array}$ & $6.2 \times 10^{-11}$ & $6.3 \times 10^{-11}$ & $1.7 \times 10^{-9}$ & $8 \times 10^{-11}$ \\
Punctual & $8.9 \times 10^{-19}$ & $9.2 \times 10^{-19}$ & $2.4 \times 10^{-17}$ & $1 \times 10^{-18}$ \\
\hline \hline
\end{tabular}

ter is closed and decreases when it is opened. An on-line tracking of the frequency shift is performed indirectly by monitoring the phase during the experiment. Since the phase slope of the $S_{21}$ parameter is negative around the resonance frequency [Fig. 3(c)], a phase decrease means a downshift of the resonance frequency that represents an increasing of the cantilever mass, Eq. (1). A total phase shift of around $9.5^{\circ}$ is observed after the experiment [Fig. 3(a)], equivalent to a change of the resonance frequency of around $1.6 \mathrm{kHz}$ [Figs. 3(b) and 3(c)] that corresponds to a total added mass of around $100 \mathrm{ng} / \mathrm{cm}^{2}$ (distributed) or $1.4 \mathrm{fg}$ (local). These results show the stability and repeatability of the device on detecting on-line small mass depositions.

An accurate electrical characterization in air conditions has been performed in order to experimentally determine the minimum detectable frequency shift and thus the mass resolution $(\delta M)$ of these devices. Figure 4 shows the magnitude and phase of the $S_{21}$ parameter obtained with $V_{\mathrm{dc}}=60 \mathrm{~V}$ and $V_{\text {ac }}=-10 \mathrm{dBm}$ into $50 \Omega$. With these conditions an electrical $Q$ factor of around 100 has been obtained. A zero-span measurement at the resonance frequency of the phase fluctuations has been performed obtaining a phase noise of $\delta \phi_{\mathrm{rms}}$ $=0.05^{\circ}$ in a readout bandwidth of $100 \mathrm{~Hz}$ (inset of Fig. 4). From the slope of the phase at the resonance frequency, we obtain the minimal frequency shift we can measure, assuming a unity signal-to-noise ratio of $\delta f_{\text {rms }}=27 \mathrm{~Hz}$. Hence, the experimental mass resolution of these devices is calculated to be as small as $\delta M=24$ ag in air conditions. An analysis of the ultimate resolution limited by the thermomechanical noise of the cantilever has been performed similar to that of Forsén et al. ${ }^{10}$ obtaining a thermomechanical-noise-limited mass resolution, with the parameters indicated in Table I, of $\delta M_{\mathrm{int}} \approx 1$ ag in air conditions.

Better resolutions have been recently reported in air conditions with ultrasensitive NEMS-based cantilever mass sensors, ${ }^{17}$ but using complex external detection instrumentation. However, results shown in the present letter and potential functionalities of the integrated CMOS circuitry as fre- quency self-tracking ${ }^{18}$ demonstrate that the technological approach presented here makes potentially possible to achieve resolutions around $1 \mathrm{ag}$ with a completely portable device. Table I summarizes the parameters of the mass sensors that indicate that the approach presented clearly offers relevant benefits in terms of sensitivity and resolution in air conditions, as well as in terms of fabrication cost and functionality.

The authors would like to thank the following people from IMB-CNM-CSIC: Marta Duch and Marta Gerbolés for postprocessing the CMOS chips as well as Julien Arcamone for helping in the preparation of the electrical setup for the time-resolved measurements. This work has been partially funded by MCYT under the project NANOSYS (TIC200307237).

${ }^{1}$ N. V. Lavrik, M. J. Sepaniak, and P. G. Datskos, Rev. Sci. Instrum. 75, 2229 (2004)

${ }^{2}$ J. Fritz, M. K. Baller, H. P. Lang, H. Rothuizen, P. Vettiger, E. Meyer, H.-J. Güntherodt, Ch. Gerber, and J. K. Gimzewski, Science 288, 316 (2000).

${ }^{3}$ H. P. Lang, M. K. Baller, R. Berger, Ch. Gerber, J. K. Gimzewski, F. M. Battison, P. Fornaro, J. P. Ramseyer, E. Meyer, and H. J. Güntherodt, Anal. Chim. Acta 393, 59 (1999).

${ }^{4}$ H. P. Lang, R. Berger, F. Battison, J.-P. Ramseyer, E. Meyer, C. Andreoli, J. Brugger, P. Vettiger, M. Despont, T. Mezzacasa, L. Scandella, H.-J. Güntherodt, Ch. Gerber, and J. K. Gimzewski, Appl. Phys. A: Mater. Sci. Process. 66, S61 (1998).

${ }^{5}$ B. Illic, D. Czaplewski, M. Zalalutdiniov, H. G. Craighead, P. Neuzil, C. Campagnolo, and C. Batt, J. Vac. Sci. Technol. B 19, 2825 (2001).

${ }^{6}$ K. L. Ekinci, X. M. H. Huang, and M. L. Roukes, Appl. Phys. Lett. 84, 4469 (2004).

${ }^{7}$ B. Illic, H. G. Craighead, S. Krylov, W. Senaratne, C. Ober, and P. Neuzil, J. Appl. Phys. 95, 3694 (2004).

${ }^{8}$ T. Ono, X. Li, H. Miyashita, and M. Esashi, Rev. Sci. Instrum. 74, 1240 (2003).

${ }^{9}$ N. V. Lavrik and P. G. Datskos, Appl. Phys. Lett. 82, 2697 (2003).

${ }^{10}$ E. Forsen, G. Abadal, S. Ghatnekar-Nilsson, J. Teva, J. Verd, R. Sandberg, W. Svendsen, F. Perez-Murano, J. Esteve, E. Figueras, F. Campabadal, L. Montelius, N. Barniol, and A. Boisen, Appl. Phys. Lett. 87, 43507 (2005).

${ }^{11}$ D. Lange, C. Hagleitner, A. Hierlemann, O. Brand, and H. Baltes, Anal. Chem. 74, 3084 (2002).

${ }^{12}$ J. Verd, A. Uranga, J. Teva, J. L. Lopez, F. Torres, J. Esteve, G. Abadal, F. Perez-Murano, and N. Barniol, IEEE Electron Device Lett. 27, 495 (2006).

${ }^{13}$ AustriaMicroSystems (AMS): $3.3 \mathrm{~V}, 0.35 \mu \mathrm{m}, 4$-metal, 2-poly CMOS process, www.austriamicrosystems.com

${ }^{14}$ J. Verd, G. Abadal, J. Teva, A. Uranga, M. Duch, F. Perez-Murano, J. Esteve, and N. Barniol,Proc. IEEE International Symposium on Circuits and Systems, 2005, Vol. 5, pp. 4209 (2005).

${ }^{15}$ K. L. Ekinci, Y. T. Yang, and M. L. Roukes, J. Appl. Phys. 95, 2682 (2004).

${ }^{16}$ This experiment was performed under base pressure of $\sim 10^{-7}$ mbar.

${ }^{17}$ M. Li, H. X. Tang, and M. L. Roukes, Nat. Nanotechnol. 2, 114 (2007).

${ }^{18}$ J. Verd, A. Uranga, J. Teva, G. Abadal, F. Torres, F. Perez-Murano, J. Esteve, and N. Barniol, Proc. IEEE International Symposium on Circuits and Systems, 2007 (to be published). 